$$
\times \frac{\mathrm{d} T}{\mathrm{~d} z}=\int_{z}^{\infty} Q \mathrm{~d} z-\int_{z}^{\infty} R \mathrm{~d} z
$$

where $x$ is the thermal conductivity of the gas which varies as $\sqrt{ } T, Q$ is the amount of energy available for heating, and $R$ is the thermal emission by the atmospheric constituents.

If we integrate this equation using the observed value of $Q$, the theoretically derived rates of emission $R$, and a $x$ value for the present composition of the upper atmosphore $\left(3 \times 10^{3}\right.$ ergs $\mathrm{cm}^{-1} \mathrm{sec}^{-1} \operatorname{deg}^{-1}$ at $\left.0^{\circ} \mathrm{C}\right)$, we find the averago exospheric emperature of the Earth to be about $1,500^{\circ} \mathrm{K}$, in agreement with what is observed. In the Holland model of the primitive atmosphere, where methane is the principal constituent, however, the situation is very different. The upper atmosphere will mainly contain free hydrogen with a thermal conductivity of $17 \cdot 3 \times 10^{3} \mathrm{ergs}^{-1} \mathrm{sec}^{-1} \operatorname{deg}^{-1}$ (at $0^{\circ} \mathrm{C}$ ). This is higher by about a factor of five than the conductivity of a nitrogen-oxygen mixture. Our calculations indicate that mainly because of the high conductivity, and also as a result of the high emission rates, $R$, in the infra-red of methane and its dissociation products, the exospheric temperature for this primitive model atmosphere would be considerably less than the present value of $1,500^{\circ} \mathrm{K}$ and would lie in the range of $500^{\circ}-900^{\circ} \mathrm{K}$, depending on the various amounts of methane and hydrogen assumed in the model. Preliminary calculations of escape indicate that for an exospheric temperature of $600^{\circ} \mathrm{K}$, a methane atmosphere, with small amounts of ammonia, nitrogen and hydrogen, could be stable against gravitational escape for as long as $10^{9} \mathrm{yr}$.

These results imply that the atmosphere required for the synthesis of amino-acids, in the Miller experiment, could have been present on the Earth during the first $10^{9} \mathrm{yr}$.

\section{S. I. RASOOL}

Institute for Space Studies,

Goddard Space Flight Center, NASA,

New York, and

Department of Meteorology and Oceanography,

New York University,

New York.

\section{W. E. MaGovern}

Department of Meteorology and Oceanography,

New York University,

New York.

Received November 4, 1966.

'Oparin, A. I., The Origin of Iife (Dover Publications, New York, 1953).

${ }^{2}$ Milter, S. L., and Urey, H. C., Science, 130, 245 (1959).

${ }^{3}$ Miller, S. L., Science. 117, 528 (1953).

*Abelson, P. H., Proc. U.S. Nat. Acad. Sci., 55, 1365 (1966). "Brown, H. "Rare Gases and the Formation of the Earth's Atmosphere", in
The Atmospheres of the Earth and Planets (edit. by Kuiper, G.), 258 The Atmospheres of the Earth and
(University of Chicago Press, 1952).

- Rubey, W. W., "Development of the Hydrosphere and Atmosphere, with Special Reference to Probable Composition of the Early Atmosphere"', in Crust of the Earth (edit. by
America, New York, 1955).

'Holland, H. D., in Petrologic Studies: a Volume in Honor of A. F. Buddington (edit. by Engel, A. E., James, H., and Ieonard, B. F.), 447 (Geological Society of America, New York, 1962).

\section{PHYSICS}

\section{Non-anti-matter Nature of the Tunguska Meteor}

THE deduction of Cowan et al. ${ }^{1}$, from their radiocarbon measurements of tree rings, that the Tunguska meteorite could not have bcen made of anti-matter has been called into question recently by R. V. Gentry ${ }^{2}$. The present cornmunication supports the assumption of Cowan et al. that thero are about $8 \pm 4$ neutrons per nucleonantinucleon annihilation and reaffirms the validity of their conclusion. Gentry has pointed out that for proton $(\mathrm{P})$-antiproton $(\overline{\mathrm{P}})$ annihilations which produce two low energy charged pions each on average, the pions decay before they can travel far enough in the atmosphere to interact; and that neutrons cannot therefore be produced to any important extent by $\overline{\mathrm{P}}-\mathrm{P}$ annihilations in the atmosphere.

Tho point that is pertinent for a meteorite made of antimatter encountering the Earth's atmosphero is that the conscquent annihilations would not be between $\mathrm{P}$ and $\overline{\mathrm{P}}$ but rather between nucleus and antinucleus. In the latter case the mean free path of pions in the nuclear matter as annihilation proceeds is very short so that they interact before escaping from the nucleus. Consequently, a great many nucleons are boiled out as energetic heavy particles, some of which are neutrons and some of which produce secondary neutrons. No direct information is available for nucleus-antinucleus annihilations, but $\overrightarrow{\mathrm{P}}$-nucleus annihilations have beon extensively studied ${ }^{3}$, and more recently $\overline{\mathrm{P}}$-deuteron (D) annihilations ${ }^{4}$.

Barkas et al. ${ }^{3}$ in examination of anti-proton annihila. tions in photographic emulsion find an average of 3.6 heavy particles per annihilation with an average energy per particle of $45 \mathrm{MeV}$ as well as $5 \cdot 3 \pm 0.4$ pions. These heavy particles are protons, deuterons and alpha particles. We can for the purposes of this discussion treat them as protons, and from charge symmetry assume that at least as many neutrons are emitted per annihilation. The neutrons which travel through the atmosphere lose very little energy by collision with the far heavier oxygen-16 and nitrogen-14, but make inelastic $(n, 2 n)$ reactions until their initial kinetic energy of $45 \mathrm{MeV}$ is reduced on the average to about $10 \mathrm{MeV}$. Thus, each neutron produces about three more neutrons, and each $\overline{\mathbf{P}}$-nucleus annihilation produces about 14 neutrons. We may guess about the nature of a nucleus-antinucleus annihilation; the probability of pions escaping is decreased because the total volume of high density nuclear and anti-nuclear matter is larger, and tho probability of heavy particles boiling out is increased. Thus, we conclude that the original assumption of Cowan et al. of $8 \pm 4$ neutrons per nucleon-antinucleon annihilation is reasonable and probably even conservative. Their deduction that their measurements "appear to set an upper limit of $1 / 7$ for the fraction of the meteorite's energy which could have been due to anti-matter" combined with the realization that anti-matter cannot exist alongside matter should be taken to mean that the probability that the meteor was made of matter instoad of anti-matter is greater than 7 to 1 .

The recent study of $\overline{\mathrm{P}} \mathrm{D}$ annihilations ${ }^{4}$ provides evidence. that already even in a nuclcus as loosely assembled as the deuteron the mean free path of pions is short. Chinowsky and Kojan ${ }^{4}$ find for $\overline{P D}$ interactions that, in about 35 per cent of the events, four or five pions and a proton of greater than $50 \mathrm{MeV}$ kinetic energy are produced, and that many of these protons have energies of several hundred $\mathrm{MeV}$. This is a very difforent result from that expected if the nucleon escaping annihilation acts as a non-participating bystander when threo pions and a low energy proton (or neutron) are produced.

This research was supported by the U.S. Atomic Energy Commission.

\section{Marshali}

\section{University of Colorado.}

Received November 7, 1966.

${ }^{1}$ Cowan, C., Atluri, C. R., and Libby, W. F., Nature, 208, 861 (1965). ${ }^{2}$ Gentry, R. V., Nature, 211. 1071 (1966).

${ }^{3}$ Barkas, W. H., Birge, R. W., Chupp, W. W., Fkspong, A. G., Goldhaber, G. Goldhaber, S., Heckman, H. H., Perkins, D. H., Sandweiss, J., Segre, E., Smith, F. M., Stork, D. H. Van Rossum, L., Amaldi, E. Baroni, G., Castognoli, C., Franzinetti, C.. and Manfredini, A., Phys. Rev., 105, 1037 (1957).

'Chinowsky, W., and Kojan, G., Nuovo Cimento, 43, 684 (1966). 